\title{
Reversibility of Ventricular Dysfunction. Clinical Experience in a Medical Office
}

\author{
Antonio Carlos Pereira Barretto
}

São Paulo, SP - Brazil

\begin{abstract}
Objective - To describe clinical observations of marked improvement in ventricular dysfunction in a medical office environment under circumstances differing from those in study protocols and multicenter studies performed in hospital or with outpatient cohorts.
\end{abstract}

Methods - Eleven cardiac failure patients with marked ventricular dysfunction receiving treatment at a doctors office between 1994 and 1999 were studied. Their ages ranged from 20 and 66 years (mean $39.42 \pm 14.05$ years); 7 patients were men, 4 were women. Cardiopathic etiologies were arterial hypertension in 5 patients, peripartum cardiomyopathy in 2 , nondefined myocarditis in 2, and alcoholic cardiomyopathy in 4. Initial echocardiograms revealed left ventricular dilatation (average diastolic diameter, $69.45 \pm 8.15 \mathrm{~mm}$ ), reduced left ventricular ejection fraction $(0.38 \pm 0.08)$ and left atrial dilatation $(43.36 \pm 5.16 \mathrm{~mm})$. The therapeutic approach followed consisted of patient orientation, elimination of etiological or causal factors of cardiac failure, and prescription of digitalis, diuretics, and angiotensinconverting enzyme inhibitors.

Results - Following treatment, left ventricular ejection fraction changed to $0.63 \pm 0.09$; left ventricular diameters changed to $57.18 \pm 8.13 \mathrm{~mm}$, and left atrium diameters changed to $37.27 \pm 8.05 \mathrm{~mm}$. Maximum improvement was noted after 16.9 \pm 8.63 (6 to 36) months.

Conclusion - Patients with serious cardiac failure and ventricular dysfunction caused by hypertension, alcoholism, or myocarditis can experience marked improvement in ventricular dysfunction after undergoing appropriate therapy within the venue of the doctor's office.

Key words: ventricular remodeling, dilated cardiomyopathy ventricular dysfunction, cardiac failure

Instituto do Coração do Hospital das Clínicas - FMUSP

Mailing address: Antonio Carlos Pereira Barretto - Rua Piave, 103 - 05620-010 São Paulo, SP - Brasil - E-mail: pereira.barretto@incor.usp.br
Morbidity and mortality associated with cardiac failure are more intense the greater the ventricular dysfunction experienced by the patient ${ }^{1,2}$. However, patients with a marked degree of ventricular dysfunction after following appropriate therapeutic intervention have significant clinical improvement, achieving survival in good condition ${ }^{3,4}$. Such survival is in many cases surprising in the face of the clinical picture presented at the initial evaluation. This effect has also been described in multicenter studies where a large number of cases were analyzed ${ }^{3-8}$.

Some doubts exist about the frequency at which such improvement occurs in clinical practice and whether reduction in ventricular dysfunction is observed in any patient with cardiac failure and whether it is more frequent in some forms of myocardial cardiopathy; also, it is not completely clear whether, in addition to observations in multicenter studies, improvement also occurs in medical practice in the doctors' offices. A meta-analysis ${ }^{9}$ of large multicenter studies observed an increase of two units in ejection fraction; for example, if ejection fraction had been 0.25 , it changed to 0.27 . A significant improvement in ventricular function leading to practical normalization was observed much more rarely. It is therefore worth pointing out that in the majority of cases only discrete reductions in ventricular diameter and small increases in ejection fraction are the rule.

We therefore decided to study the methods of medical practice in the doctor's office to evaluate the improvement in ventricular dysfunction in patients who receive treatment under clinical conditions differing from those prevailing in large multicenter studies.

\section{Methods}

Eleven patients with marked ventricular dysfunction that improved markedly following therapeutic intervention were studied. Seven patients were men, four were women; ages ranged from 20 and 66 years, averaging $39.9 \pm 14$ (SD) years; studies covered the period between 1994 and 1999.

Case histories, physical examination, echocardiograms, and other information were collected from all 
patients. After an initial orientation about cardiac decompensation factors, all subjects were told to decrease sodium and water ingestion and were given digoxin, diuretic drugs, and angiotensin-converting enzyme inhibitors. Ventricular dysfunction judged based on work selection criteria improved in all study participants.

Digoxin was given at the usual dosage of $0.25 \mathrm{mg} /$ day. Diuretics given were a thiazide drug and furosemide. The diuretic dosage was reduced as the patient's condition improved and essentially was suspended in all those with improved ventricular dysfunction. Seven patients received enalapril; 1 at $10 \mathrm{mg} / \mathrm{day}, 2$ at $10 \mathrm{mg} / 2 \mathrm{x}$ per day, and 4 at $20 \mathrm{mg} /$ day; 4 received captopril at $25 \mathrm{mg} / 3 \mathrm{x} /$ day. Angiotensinconverting enzyme inhibitor administrations were maintained in all patients until the final evaluation.

\section{Results}

All patients experienced limiting dyspnea, whether in the decubitus or following minimal effort. Hepatomegaly and lower limb edema (functional class III or IV, according to the New York Heart Association criteria) were also observed.

On the echocadiogram, left ventricular diastolic diameters ranged from 62 to $90 \mathrm{~mm}(69.45- \pm 8.15 \mathrm{~mm}$ average). Fractions ejected from the left ventricle ranged from 0.26 to 0.48 $(0.38 \pm 0.08$ average $)$; left atria diameters ranged from 36 to $48 \mathrm{~mm}$ (mean 43.36 $\pm 5.1 \mathrm{~mm}$ ) (figures 1 and 2).

Heart failure was attributed to arterial hypertension in 5 cases, to peripartum cardiomyopathy in 2 , to myocarditis of undetermined etiology (probably viral) in 2, and to alcoholic cardiomyopathy associated with arterial hypertension

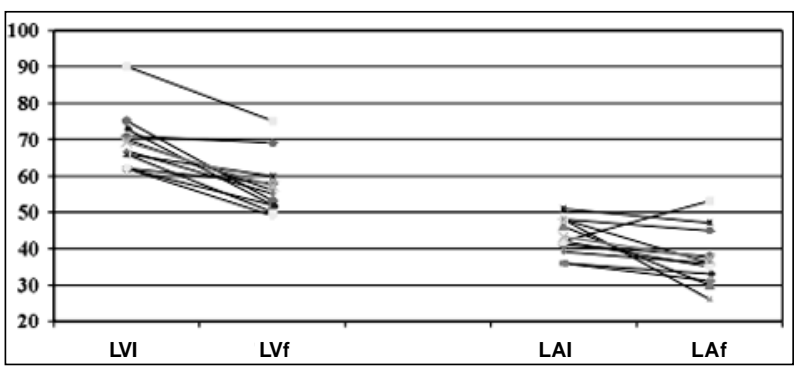

Fig. 1 - Left ventricle and left atrium diameters at the beginning and end of the followup period. Lvi- initial left ventricle diameter; LVf- final left ventricle diameter; Laiinitial left atrium diameter; Laf- final left atrium diameter.

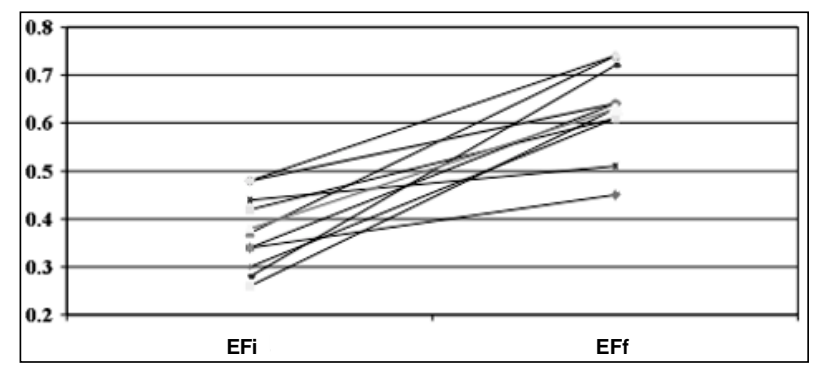

Fig. 2 - Ejection fraction evaluated at the beginning and the end of the follow-up period. Efi- initial ejection fraction from the left ventricle; Eff- final ejection fraction from the left ventricle. in 2 (Table I). The cases of myocarditis and peripartum cardiomyopathy showed a positive gallium uptake response.

It was possible to stop diuretic and digoxin administration to all patients with the exception of one who maintained an ejection fraction of 0.45 . The administration of angiotensin-converting enzyme inhibitors was maintained even though it could have been suspended in most patients, who had ejection fractions above 0.45 after treatment, a value considered the limit for inhibitor indication. The use of the inhibitors was nevertheless maintained because they had played an important role in the reversal of patients' clinical picture and because many patients were reluctant to suspend this medication despite their significant clinical improvement. All patients tolerated the doses of inhibitors prescribed and did not have collateral effects, which could have indicated a need for suspension or dose reduction of the drugs.

Following an average period of $16.9 \pm 8.63$ ( 6 to 36 ) months, reduction in left ventricular dilatation was observed, mean ventricular diameters changed from $69.45 \mathrm{~mm}$ to $57.18 \mathrm{~mm}$; left atria diameters changed from $43.36 \mathrm{~mm}$ to $37.27 \mathrm{~mm}$ (Tables I and Figure 1). Mean ejection fraction from the left ventricle increased from 0.38 to 0.63 (Figure 2).

Follow-up of the patients to the present day shows that none of them have a worsening in ventricular dysfunction; no deaths have been recorded.

\section{Discussion}

Evidence has demonstrated that it is possible to modify the natural history of cardiac failure with angiotensinconverting enzyme inhibitors ${ }^{3-5}$, beta-blockers ${ }^{6,7}$, and spironolactone $^{8}$.

Experience has also shown that patients can experience regression or a marked decrease in ventricular dysfunction following such treatments. In the present work, we describe 11 cases showing this regression; the majority were highly symptomatic patients, and many had been suggested as candidates for possible heart transplantation. In these cases, significant improvement in ventricular function leading to practical normalization-remains a rather rare outcome.

We should point out that the etiological diagnosis of our 11 cases falls into the category recognized as having reversible causes of ventricular dysfunction, namely arterial hypertension ( 5 cases), peripartum cardiomyopathy ( 2 cases), myocarditis (2 cases), and alcoholic cardiomyopathy (4 cases). Although this is a small cohort, it may be considered as expressive, because these patients were the only ones experiencing a regression in ventricular dysfunction of the many patients treated at this doctor's office. It is our experience that the large majority of cases showing symptom improvement following treatment remain without great alterations in echocardiographic parameters. We did however observe that a significant percentage of patients stabilized by treatment remained clinically stable for years; however, 


\begin{tabular}{|c|c|c|c|c|c|c|c|c|c|c|c|}
\hline \multirow[t]{2}{*}{$\mathrm{N}$} & \multirow{2}{*}{$\begin{array}{l}\text { Age } \\
\text { (y) }\end{array}$} & \multirow[t]{2}{*}{ Sex } & \multirow[t]{2}{*}{ Etiology } & \multirow[t]{2}{*}{ Diameter $(\mathrm{mm})$} & \multicolumn{2}{|c|}{ LV } & \multicolumn{2}{|c|}{ LA } & \multicolumn{2}{|c|}{$\mathrm{EF}$} & \multirow[t]{2}{*}{ regression } \\
\hline & & & & & I & $\mathrm{F}$ & I & $\mathrm{F}$ & I & $\mathrm{F}$ & \\
\hline 1 & 49 & $\mathrm{~F}$ & Hypertensive & & 71 & 69 & 0.34 & 0.45 & 48 & 45 & 12 \\
\hline 2 & 33 & F & Peripartum & & 66 & 50 & 0.26 & 0.63 & 48 & 36 & 18 \\
\hline 3 & 20 & M & Myocarditis & & 62 & 52 & 0.37 & 0.74 & 46 & 30 & 7 \\
\hline 4 & 27 & $\mathrm{~F}$ & Peripartum & & 70 & 56 & 0.37 & 0.64 & 48 & 26 & 24 \\
\hline 5 & 66 & $\mathrm{M}$ & Hyp/alc & & 66 & 60 & 0.44 & 0.51 & 51 & 47 & 12 \\
\hline 6 & 37 & $\mathrm{M}$ & Hyp/alc & & 75 & 53 & 0.48 & 0.64 & 41 & 38 & 24 \\
\hline 7 & 41 & $\mathrm{~F}$ & Myocarditis & & 67 & 55 & 0.30 & 0.61 & 39 & 36 & 15 \\
\hline 8 & 62 & M & Alcoholism & & 73 & 52 & 0.28 & 0.72 & 36 & 33 & 18 \\
\hline 9 & 36 & $\mathrm{M}$ & Alcoholism & & 62 & 58 & 0.48 & 0.64 & 36 & 31 & 14 \\
\hline 10 & 37 & $\mathrm{M}$ & Hypertensive & & 62 & 49 & 0.48 & 0.74 & 42 & 35 & 36 \\
\hline 11 & 31 & $\mathrm{M}$ & Hypertensive & & 90 & 75 & 0.42 & 0.61 & 42 & 53 & 6 \\
\hline
\end{tabular}

regressions, as presently related, were only observed in these 11 cases. Of them, arterial hypertension and alcoholic myocardiopathy were the most frequent. Poorly controlled hypertension by overloading the left ventricle may lead to ventricular dysfunction, a late complication observed in cases of moderate and intense arterial hypertension. According to the Hypertension Detection Follow-up study, measures to lower blood pressure levels to less than $140 / 90 \mathrm{~m}$ $\mathrm{mHg}$ will control the near totality of these cases. Our 5 cases are an example of this ${ }^{10}$.

Alcoholism is a cause of cardiomyopathy that, following interruption of alcohol consumption, may result in a regression in myocardial impairment ${ }^{11}$. This regression depends on the length and intensity of exposure to alcoholism as well as the type of the myocardial lesion. Prolonged, continuous aggression consequent to established fibrosis may lead to incomplete or even the lack of regression. In the majority of cases, avoidance of alcohol leads to regression in ventricular dysfunction, which however may reappear following a return to alcoholism. Although more frequent among drinkers of brazilian rum or sugar-cane rum, dysfunction can also be due to the ingestion of any kind of alcoholic beverage. In our cohort, all subjects were beer drinkers, but frequently also ingested distilled liquor.

The third type of diagnosis, myocarditis, probably includes myocarditis proper as well as peripartum cardiomyopathy. Although the latter does not have a well-defined etiopathogeny, an inflammatory process could be detected in a significant percentage of patients, pointing towards the supposition that peripartum cardiomyopaths are a consequence of a myocarditic picture ${ }^{12-14}$. Work from our institution has shown that the closer in time to parturition that biopsies for peripartum cardiomyopaths are performed, the greater the incidence of inflammation becomes ${ }^{12}$.

Cases of myocarditis are also recognized as reversible cardiomyopathies ${ }^{13,14}$. Results indicate that the majority of cases of myocarditis show spontaneous regression. Although a possible cause of dilated myocardiopathy, actually a final phase of many cases of myocarditis that fail to recede, dilated cardiomyopathy is a rare complication within the universe of myocardities. Regression is so frequent that studies using specific treatment with immunospressors, corticoid drugs, or antiimmunoglobulin antibodies; did not show results above those of placebo, which also had a pronounced trend towards regression in ventricular dysfunction. For example, in the Myocarditis Trial ejection fraction rose from 0.36 to 0.46 , regardless of treatment used, either placebo or corticosteroids in association with cyclosporine ${ }^{15}$.

An interesting aspect of the experiment was the slowness of the regression ventricular dysfunction. On average, the period required for its normalization was 16.9 months, with a variation between 6 and 36 months. These figures are of importance because they provide guidance about the time intervals required for patient re-evaluation. Because regression does not occur very rapidly, monthly re-evaluations are not necessary. Our practice is to repeat the first evaluation after 3 months and every 6 months thereafter.

The prognosis was good in these cases, and no deaths occurred during the 3- to 5-year follow-up period. Such improved evolution of patients with ventricular dysfunction has already been referred to in the literature ${ }^{4,16,17}$. In the Veterans Heart Failure Study (VeHFT), the evolution of patients who had increases in ejection fraction was much better than in those who remained stable or had a reduction ${ }^{4}$.

In the results of the VeHFT Study ${ }^{4}$, variations in ejection fraction were divided into 4 groups comprising, respectively, patients who got worse, who had no change, who had a 5\% to $10 \%$ increase, and those having an increase over $10 \%$ increase. Survival times of these 4 groups were statistically different, the most expressive one being shown by the group having over $10 \%$ increases of their ejection fractions. At the end of the study, mortality in the 4 groups was, respectively, $21 \%, 11 \%, 6.7 \%$, and $3 \%$. Patients experiencing the most significant improvement in ejection fraction also had the most significant clinical improvement.

Improved ventricular function in patients with recently acquired ventricular dysfunction has been described in over $37 \%$ of the cases treated at a transplantation clinic in California.

Steimle et al. ${ }^{16}$ cited 13 patients in whom increases in ejection fractions from 0.22 to 0.49 (mean of 0.27 ) were observed. This increase, similar to that shown in our study, 
was accompanied by a reduction in ventricular diameters from $67 \mathrm{~mm}$ to $59 \mathrm{~mm}$. None of the patients died during the follow-up period that averaged 43 month (8 to 112 months).

Kawai et al. ${ }^{17}$ also observed a better evolution in patients, who evolved to improved ejection fraction ${ }^{5}$. They followed 88 patients who had idiopathic dilated cardiomyopathy with an ejection fraction below $25 \%$, who had been discharged between 1984 and 1996 following hospitalization for compensation. Twenty (26\%) of these patients had significant reverse remodeling, either a 5- mm reduction in ventricular diameter, or diameters remaining below $55 \mathrm{~mm}$ and an ejection fraction above $25 \%$, or with a reduction in left ventricular mass of over $10 \%$. As a matter of fact, reverse remodeling has been shown to be an important prognostic factor, characterizing groups with the best evolution ${ }^{6-18}$. In this work, patients were treated with angiotensin-converting enzyme inhibitors (81\%), and beta-blockers (59\%). The improved cardiac function was an important prognostic factor, because during an evolutionary period of 50 months, none of the patients who had had reverse remodeling died or had to be hospitalized due to cardiac failure. In contrast, 16 (28\%) patients not having such improvement died, and 22 (39\%) had to be rehospitalized.

These data allow one to conclude that regression in ventricle dysfunction can occur even in the environment of a doctor's office, potentially identifying patients having a better prognosis. Improvement in this dysfunction is not rapid and may require more than 1 year to reach completion. Patients having cardiomyopathies of a defined etiology like alcoholism, peripartum cardiomyopaths, myocarditis (in this case without defined etiology), or arterial hypertension were, in our experience, among those having this regression.

\section{References}

1. Bocchi EA. Situação atual das indicações e resultados do tratamento cirúrgico da insuficiência cardíaca. Arq Bras Cardiol 1994; 63: 523-30.

2. Oliveira Jr MT. Características clínicas e prognóstico de pacientes chagásicos e não chagásicos com insuficiência cardíaca congestiva avançada. Tese doutoramento. Faculdade de Medicina da Universidade de São Paulo, São Paulo, 1999.

3. The SOLVD Investigators. Effect of enalapril on survival in patients with reduced left ventricular ejection fraction and congestive hear failure. N Engl J Med 1991; 325: 293-302.

4. Cintron G, Johnson G, Francis G, Cobb F, Cohn J for the V-HeFT VA. Cooperative Studies Group. Prognostic significance of serial changes in left ventricular ejection fraction in patients with congestive heart failure. Circulation 1993; 87(suppl VI):VI-17-V1-23.

5. The Acute Infarction RamiprilEfficacy (AIRE) Study Investigators. Effect of ramipril on mortality and morbidity of survivors of acute myocardial infarction with clinical evidence of heart failure. Lancet 1993; 342: 821-8.

6. Packer M, Collucci WS, Sackner-Bernstein JD, et al. Double-blind, placebo-controlled study of the effects of carvedilol in patients with moderate to severe heart failure. The PRECISE trial. Circulation 1996; 94: 2793-9.

7. Cibis-II Investigators and committees. The cardiac insufficiency bisoprolol study (CIBIS-II): a randomized trial. Lancet 1999; 353: 9-13.

8. Pitt B, Segal R, MartinezFA, et al. Randomized trial of losartan versus captopril in patients over 65 with heart failure (Evaluation of Losartan in the Elderly Study, ELITE). Lancet 1997; 349: 747-52.
9. Massie B. 15 years of heart failure trials: what have we learned? Lancet 1998; 352(suppl I): 29-33.

10. Hypertension Detection and Follow-up Program Cooperative Group. The effect of treatment on mortality in mild hypertension N Engl J Med 1982; 307: 976-80.

11. Jacob AJ, McLaren KM, Boon NA. Effects of abstinence on alcoholic heart muscle disease. Am J Cardiol 1991; 68: 805-7.

12. Mady C, Pereira Barretto AC, BellottiG, et al. Biópsia endomiocárdica em pacientes portadores de miocardiopatia periparto. Arq Bras Cardiol 1986; 47: 403-5.

13. Glasier JJ, Constanzo-Nordin MR. Specific heart muscle disease. Cur Opin Cardiol 1993; 8: 454-62

14. Sliwa K, Skudicky D, Bergemann A, et al. Peripartum cardiomyopathy: Analysis of clinical outcome, left ventricular function, plasma levels of cytokines and Fas/ APO-1. J Am Coll Cardiol 2000; 35: 701-5.

15. Mason JW, O'Connell JB, Herskowitiz A, et al. A clinical trial of immunosuppressive therapy for myocarditis. N Engl J Med 1995; 333: 269-75.

16. Steimle AE, Stevenson LW, Fonarow GC, Hamilton MA, Moriguchi JD. Prediction of improvement in recent onset cardiomyopathy after referral heart transplantation. J Am Coll Cardiol 1994; 23: 553-9.

17. Kawai K, Takaoka H, Hata K, Yokota Y, Yokoyama M. Prevalence, predictors, and prognosis of reversal of maladaptive remodeling with intensive medical therapy in idiopathic dilated cardiomiopathy. Am J Cardiol 1999; 84: 671-6.

18. Patten RD, Udelson JE, Konstam MA. Ventricular remodeling and its prevention in the treatment of heart failure. Cur Opin Cardiol 1998; 13: 162-7. 